\title{
Tempol inhibits growth of As4.1 juxtaglomerular cells via cell cycle arrest and apoptosis
}

\author{
YONG HWAN HAN and WOO HYUN PARK \\ Department of Physiology, Research Institute for Endocrine Sciences, \\ Chonbuk National University Medical School, Jeonju 561-180, Republic of Korea
}

Received August 30, 2011; Accepted October 7, 2011

DOI: $10.3892 /$ or.2011.1518

\begin{abstract}
A stable nitroxide 4-hydroxy-2,2,6,6-tetramethylpiperidine-N-osyl (Tempol) is widely used as an antioxidant in vitro and in vivo. In this study, we investigated the effects of Tempol on the growth of As4.1 juxtaglomerular cells in relation to cell cycle and cell death. Tempol dose-dependently decreased the growth of As4.1 cells with an $\mathrm{IC}_{50}$ of $\sim 1 \mathrm{mM}$ at $48 \mathrm{~h}$. DNA flow cytometry analysis and BrdU staining indicated that Tempol induced $\mathrm{S}$ phase arrest, which is accompanied by a downregulation of cyclin A. Tempol also induced apoptotic cell death, which was accompanied by the loss of mitochondrial membrane potential (MMP; $\Delta \Psi \mathrm{m}$ ), an activation of caspase-3 and cleavage of poly(ADP-ribose)polymerase-1 (PARP-1). Furthermore, Tempol increased reactive oxygen species (ROS) levels, and the phosphorylation of extracellular signal-regulated kinase (ERK) and c-Jun N-terminal kinase (JNK). MEK and JNK inhibitors significantly attenuated a growth inhibition in Tempol-treated As4.1 cells. In conclusion, Tempol inhibited the growth of As4.1 cells via cell cycle arrest and apoptosis. Tempol also activated ERK and JNK signaling, which was responsible for cell growth inhibition. Our present data provide useful information for the toxicological effects of Tempol in juxtaglomerular cells in relation to cell growth inhibition and cell death.
\end{abstract}

Correspondence to: Dr Woo Hyun Park, Department of Physiology, Chonbuk National University Medical School, Jeonju 561-180, Republic of Korea

E-mail: parkwh71@chonbuk.ac.kr

Abbreviations: ROS, reactive oxygen species; BrdU, Bromodeoxyuridine; BrdU, 5-Bromo-2'-deoxyuridine; CDK, cyclin dependent kinase; CDKI, cyclin dependent kinase inhibitor; ERK, extracellular signal-regulated kinase; FBS, fetal bovine serum; JNK, c-Jun N-terminal kinase; MAPK, mitogen-activated protein kinase; MMP, mitochondrial membrane potential; PARP-1, poly(ADP-ribose)polymerase-1; Rb, Retinoblastoma; Tempol, 4-hydroxy-2,2,6,6-tetramethylpiperidine-1-oxyl

Key words: juxtaglomerular cells, Tempol, cell cycle, apoptosis, MAPK

\section{Introduction}

Tempol (4-hydroxy-2,2,6,6-tetramethylpiperidine-N-oxyl or 4-hydroxy-tempo) is a stable piperidine nitroxide, which is widely employed in electron spin resonance spectroscopy (1). It is also known that Tempol protects cells from oxidative damage in vitro and in vivo (2). Several antioxidant mechanisms have been proposed to account for these protective effects. It may act as a mimic of superoxide dismutase (SOD) and it can reduce the formation of hydroxyl radicals either by scavenging superoxide anion or by reducing intracellular concentration of $\mathrm{Fe}(\mathrm{II})$ (3). Usually, such beneficial effects are observed up to a few $\mu \mathrm{M}$. However, the prospect of moving it from the experimental to the clinical arena has prompted more detailed studies on their possible toxicity. Much evidence suggests that Tempol impairs ferritin synthesis and Fe metabolisms, consequently leading to cell death (4). In addition, mutagenic effects has been reported in different bacterial strains (5). Of note, Tempol as a pro-oxidant induces the cell cycle arrest and apoptosis depending on cell types (6). Therefore, in order to clarify these discrepancies among the different effects of Tempol, further study needs to be performed for re-evaluating its real biological functions and roles.

The mitogen-activated protein kinases (MAPKs) are a large family of serine/threonine kinases, which are major components of signaling pathways in cell proliferation, differentiation, and cell death (7). There are currently three known MAPKs: the extracellular signal-regulated kinase (ERK1/2), the c-Jun $\mathrm{N}$-terminal kinase/stress-activated protein kinase (JNK/SAPK) and the p38 (7). Each MAPK pathway has relatively different upstream activators and specific substrates (7). Accumulating evidence demonstrates that JNK and p38 are strongly activated by ROS and/or a mild oxidative shift of the intracellular thiol/ disulfide-redox state, leading to apoptosis $(8,9)$. ROS are also known to induce ERK phosphorylation and activate ERK pathway (10). In most instances, ERK activation has been by the prosurvival functions rather than proapoptotic effects (11).

Tempol protects cells from oxidative damage in vivo (2) and this drug can easily affect kidney cells, especially juxtaglomerular cells. However, little is known about the cytotoxic relationship between Tempol and juxtaglomerular cells. In this study, we evaluated the effects of Tempol on the growth of As4.1 juxtaglomerular cells and its mechanisms in relation to the cell cycle and cell death. 


\section{Materials and methods}

Cell culture. As 4.1 cells obtained from the American Type Culture Collection (ATCC). Cells were maintained in humidified incubator containing $5 \% \mathrm{CO}_{2}$ at $37^{\circ} \mathrm{C}$. As4.1 cells were cultured in Dulbecco's modified Eagle's medium (DMEM) supplemented with $10 \%$ fetal bovine serum (FBS) and $1 \%$ penicillin-streptomycin (Gibco BRL, Grand Island, NY). Cells were routinely grown in 100-mm plastic tissue culture dishes (Nunc, Roskilde, Denmark) and harvested with a solution of trypsin-EDTA (0.05\% trypsin and $0.53 \mathrm{mM}$ EDTA) while in a logarithmic phase of growth. Cells were maintained in these culture conditions for all experiments.

Reagents. Tempol was purchased from the Sigma-Aldrich Chemical Co. (St. Louis, MO, USA) and was dissolved in methanol at $1 \mathrm{M}$ as a stock solution. JNK inhibitor (SP600125), MEK inhibitor (PD98059), and p38 inhibitor (SB203580) were purchased from Calbiochem (San Diego, CA). These agents were dissolved in DMSO solution at $10 \mathrm{mM}$ as a stock solution. All inhibitors were added $1 \mathrm{~h}$ prior to Tempol treatment. Unless indicated otherwise, chemicals were purchased from Sigma.

Cell growth assay. The effect of Tempol on As4.1 cell growth was determined by trypan blue exclusion cell counting or measuring 3-(4,5-dimethylthiazol-2-yl)-2,5-diphenyltetrazolium bomide (MTT) dye absorbance of living cells as previously described (12). Results were calculated as a percentage of the absorbance or total cell number measured in untreated control cells.

Cell cycle analysis. Cell cycle distributions in cells were determined by propidium iodide (PI, Sigma; Ex/Em=488/617 nm) staining as previously described (12). Cell DNA content was measured using a FACStar flow cytometer (Becton-Dickinson, San Jose, CA, USA) and analyzed suing lysis II and CellFit software (Becton-Dickinson).

BrdU incorporation assay. Bromodeoxyuridine (BrdU) incorporation into DNA was detected by an immunoassay. Briefly, the cells were incubated with $2 \mathrm{mM}$ Tempol for $48 \mathrm{~h}$. After adding BrdU in culture medium to a final concentration of $10 \mu \mathrm{M}$, cells were incubated for $30 \mathrm{~min}$ in a $\mathrm{CO}_{2}$ incubator at $37^{\circ} \mathrm{C}$. After removal of the culture medium, the cells were collected and fixed with $70 \%$ ethanol. Cells were denatured in $2 \mathrm{~N} \mathrm{HCl}$ at $37^{\circ} \mathrm{C}$ for $30 \mathrm{~min}$, washed and neutralized in $0.1 \mathrm{M}$ sodium borate $\left(\mathrm{Na}_{2} \mathrm{~B}_{4} \mathrm{O}_{7}, \mathrm{pH} 8.5\right)$ for $30 \mathrm{~min}$. Mouse anti-BrdU/FITC monoclonal antibody (Dako Cytomation, Glostrup, Denmark) was diluted 10-fold in PBS with $1 \%$ bovine serum albumin (BSA) and $0.5 \%$ Tween-20 at $4^{\circ} \mathrm{C}$ for 30 min. Cells were then washed with PBS containing $1 \%$ BSA and $0.5 \%$ Tween-20 and resuspended in PBS containing PI $(10 \mu \mathrm{g} / \mathrm{ml} \mathrm{PI})$. BrdU incorporation was analyzed on a flow cytometer (Becton-Dickinson).

Western blot analysis. The expression of proteins was evaluated by Western blot analysis as previously described (13). Supernatant samples containing $20 \mu \mathrm{g}$ total proteins were resolved by $12.5 \%$ SDS-PAGE gel, transferred to Immobilon-P PVDF membranes (Millipore, Billerica, MA, USA) by
A

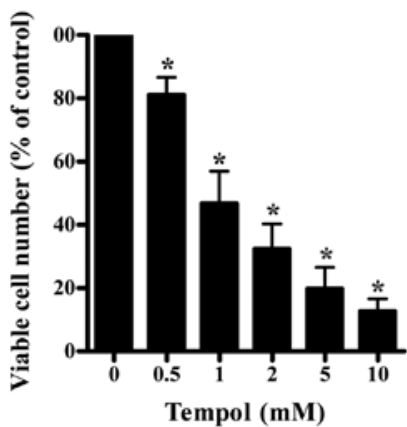

B

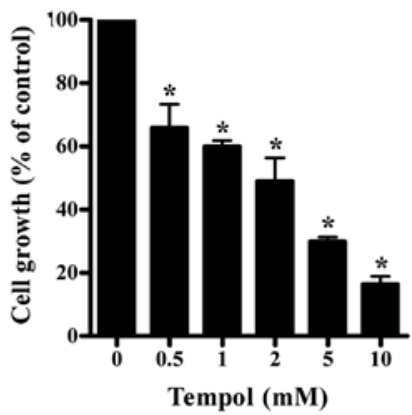

Figure 1. Effects of Tempol on the growth of As4.1 cells in vitro. Exponentially growing cells were treated with the indicated concentration of Tempol for $48 \mathrm{~h}$. Viable cell number (A) and Cell growth (B) were assessed by trypan blue exclusion cell counting and an MTT assay, respectively. ${ }^{*} \mathrm{p}<0.05$ compared with the Tempol-untreated control cell group.

electroblotting, and probed with anti-cyclin E, anti-cyclin A, anti-p27, anti-actin, anti-cyclin dependent kinase (CDK) 2, anti-PARP (Santa Cruz Biotechnology, Santa Cruz, CA, USA), anti-phospho-ERK and anti-phospho-JNK antibodies (Cell Signaling Technology, Inc., Danvers, MA, USA). Membranes were incubated with horseradish peroxidase-conjugated secondary antibodies. Blots were developed using an ECL kit (Amersham, Arlington Heights, IL, USA).

Annexin V staining. Apoptosis was determined by staining cells with Annexin V-fluorescein isothiocyanate (FITC) $(\mathrm{Ex} / \mathrm{Em}=488 / 519 \mathrm{~nm})$ as previously described (14). In brief, $1 \times 10^{6}$ cells were incubated with the designated doses of Tempol with or without MAPK inhibitors for $48 \mathrm{~h}$. Cells were washed twice with cold PBS and then resuspended in $500 \mu \mathrm{l}$ of binding buffer (10 mM HEPES/NaOH pH 7.4, 140 mM NaCl, $2.5 \mathrm{mM}$ $\mathrm{CaCl}_{2}$ ) at a concentration of $1 \times 10^{6}$ cells $/ \mathrm{ml}$. Five microliters of Annexin V-FITC (Molecular Probe, USA) was then added to these cells, which were analyzed with a FACStar flow cytometer (Becton-Dickinson).

Quantification of caspase-3 activity. The activity of caspase-3 was assessed using caspase-3 Colorimetric Assay kits (R\&D Systems, Inc.) according to the manufacturer's instructions. In brief, $1 \times 10^{6}$ cells were incubated with the designated doses of Tempol for $48 \mathrm{~h}$ then washed in PBS and suspended 5 volumes of lysis buffer (20 mM HEPES pH 7.9, 20\% glycerol, $200 \mathrm{mM}$ $\mathrm{KCl}, 0.5 \mathrm{mM}$ EDTA, 0.5\% NP40). Protein concentration was determined by the Bradford method. Supernatant samples containing $100 \mu \mathrm{g}$ total proteins were added to DEVD-PNA in 96-well microtiter plates (Nunc) and incubated at $37^{\circ} \mathrm{C}$ for $1 \mathrm{~h}$. Optical density was measured at $405 \mathrm{~nm}$ using a microplate reader (Spectra MAX 340, Molecular Devices Co.). Each plate 
A

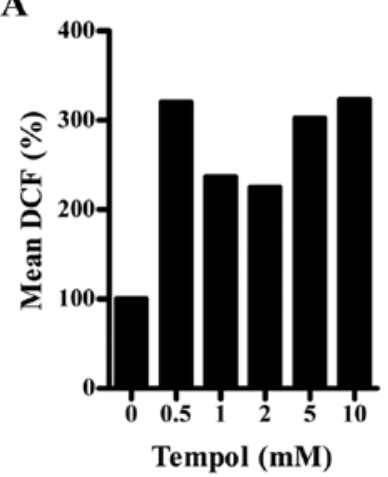

B

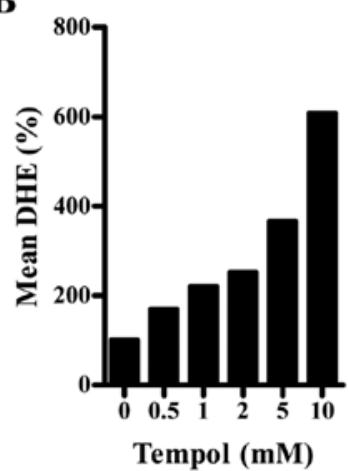

C

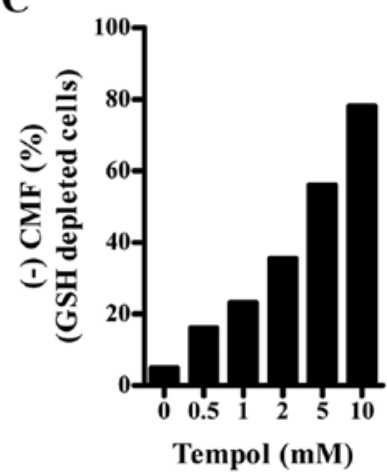

Figure 2. Effect of Tempol on intracellular ROS levels and GSH depletion. Exponentially growing cells were treated with the indicated concentration of Tempol for $48 \mathrm{~h}$. Intracellular ROS levels (A and B) and GSH depletion (C) were assessed by flow cytometry.

contained multiple wells of a given experimental condition and multiple control wells.

Measurement of MMP $(\Delta \Psi m)$. The MMP $(\Delta \Psi \mathrm{m})$ was measured using the Rhodamine 123 fluorescent dye $(E x / E m=485 / 535 \mathrm{~nm})$, which preferentially enters mitochondria (13). In brief, $1 \times 10^{6}$ cells were incubated with the designated doses of Tempol for $48 \mathrm{~h}$. Cells were washed twice with PBS and incubated with Rhodamine $123\left(0.1 \mu \mathrm{g} / \mathrm{ml}\right.$; Sigma) at $37^{\circ} \mathrm{C}$ for $30 \mathrm{~min}$. Rhodamine 123 staining intensity was determined by flow cytometry. Rhodamine 123 negative cells indicate the loss of $\operatorname{MMP}(\Delta \Psi \mathrm{m})$ in cells.

Detection of intracellular ROS and GSH. Intracellular ROS were detected by means of an oxidation-sensitive fluorescent probe dye 2',7'-dichlorodihydrofluorescein diacetate (H2DCFDA, Invitrogen Molecular Probes, OR; $\mathrm{Ex} / \mathrm{Em}=495 / 529 \mathrm{~nm}$ ) and dihydroethidium (DHE, Invitrogen Molecular Probes, OR; Ex/Em=510/580 nm) (15). Cellular GSH levels were analyzed suing 5-chloromethylfluorescein diacetate (CMFDA, Invitrogen Molecular Probes; Ex/Em=522/595 nm) (15). ROS and GSH levels were expressed as mean fluorescence intensity (MFI), which was calculated by CellQuest software (Becton-Dickinson).

Statistics. The results represent the mean of at least three independent experiments (mean $\pm \mathrm{SD}$ ). The data were analyzed using Instat software (GraphPad Prism4, San Diego, CA). The Student's t-test or one-way analysis of variance (ANOVA) with post hoc analysis using Tukey's multiple comparison test was used for parametric data. Statistical significance was defined as $\mathrm{p}<0.05$.

\section{Results}

Effects of Tempol on the growth of As4.1 cells. We examined the effects of Tempol on the growth of As4.1 cells by trypan blue cell counting. Treatment with $0.5-10 \mathrm{mM}$ Tempol significantly decreased the population of cells for $48 \mathrm{~h}$ in a dose-dependent manner (Fig. 1A). When the growth of As4.1 cells was also investigated by an MTT assay, dose-dependent reduction of cell growth was observed in As4.1 cells with an $\mathrm{IC}_{50}$ of $1 \mathrm{mM}$ following treatment with Tempol for $48 \mathrm{~h}$ (Fig. 1B).
Effects of Tempol on intracellular ROS and GSH levels in As4.1 cells. Next, we determined whether Tempol changes the intracellular ROS and GSH levels. As shown in Fig. 2A, ROS (DCF) levels were increased in Tempol-treated As4.1 cells. Red fluorescence derived from DHE, which reflected $\mathrm{O}_{2}^{-{ }^{-}}$accumulation, was also increased in As4.1 cells treated with Tempol at $48 \mathrm{~h}$ (Fig. 2B). In relation to GSH, Tempol increased GSH depleted cell number in As4.1 cells (Fig. 2C).

Effects of Tempol on the cell cycle distribution in As4.1 cells. We examined the effect of Tempol on the cell cycle distribution in live As4.1 cells without sub-G1 DNA content cells. As shown in Fig. 3A, DNA flow cytometric analysis indicated that treatment with 0.5-2 $\mathrm{mM}$ Tempol markedly induced an S phase arrest of the cell cycle at $48 \mathrm{~h}$. However, relatively higher dose of Tempol did not alter the cell cycle distribution (Fig. 3A). To confirm the Tempol-induced S phase arrest in As4.1 cells, we examined BrdU incorporation assay. Consistent with the DNA flow cytometric analysis, the number of BrdU-positive cells was increased in Tempol-treated As4.1 cells (Fig. 3B). Next, we determined the levels of $\mathrm{S}$ phase-related proteins. While treatment with Tempol down-regulated cyclin-dependent kinase inhibitor (CDKI) p27 and cyclin A, it up-regulated CDK2 and cyclin E expression (Fig. 3C).

Effects of Tempol on cell death and MMP $(\Delta \Psi m)$ in As4.1 cells. Next, we determined whether Tempol induces cell death in As4.1 cells using Annexin V/PI staining. As shown in Fig. 4A, the proportion of Annexin V-staining cells in Tempol-treated cells was increased in a dose-dependent manner, which indicates that Tempol-induced As4.1 cell death occurred via apoptosis. In addition, treatment with Tempol augmented PI (+)/Annexin (-) staining cells, which represents necrotic cell death. Caspase-3 plays an essential role as an executioner in apoptosis (16). Therefore, we examined whether Tempol activates caspase-3 during the induction of apoptosis in As4.1 cells. The activity of caspase-3 was significantly elevated in Tempol-treated cells as compared with the control cells (Fig. 4B), which suggest that the activation of caspase-3 occurred in Tempol-treated cells. In regard to PARP-1 protein, which is a major substrate for executed caspases and a hallmark of apoptosis, Western blotting showed that cleaved $89 \mathrm{kDa}$ moiety of PARP was increased 
A

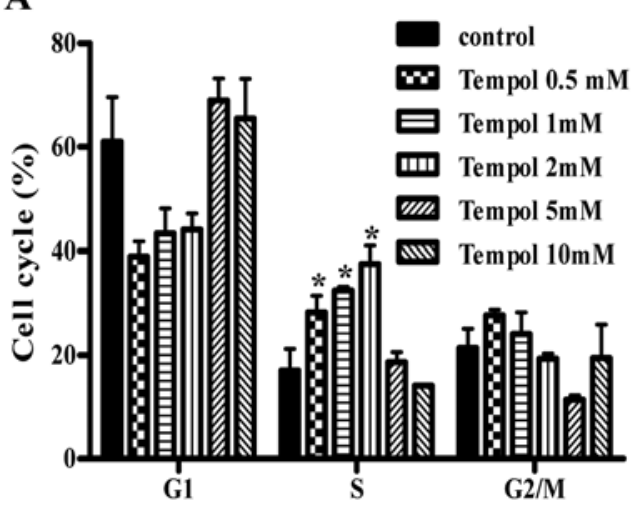

B

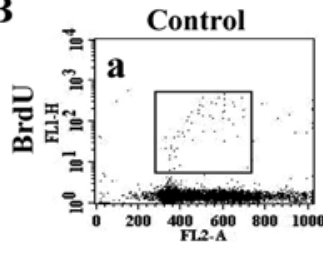

C

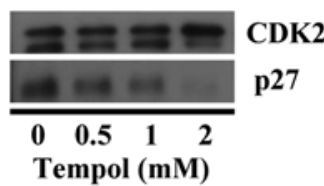

Control
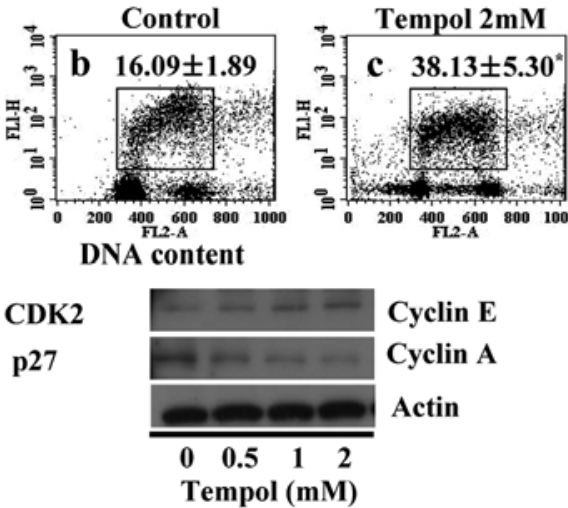

Figure 3. Effect of Tempol on the cell cycle distribution in As4.1 cells. Exponentially growing cells were treated with the designated concentrations of Tempol for $48 \mathrm{~h}$. (A) The changes of cell cycle phase distribution were assessed by DNA flow cytometric analysis. (B) BrdU incorporation was detected by flow cytometer. The region in square indicates S phase of cell cycle distribution. (a) The negative control treated with PBS instead of BrdU (b) Tempol-untreated As4.1 cells (c) Tempol-treated As4.1 cells. (C) The expression of cell cycle-related proteins was determined via Western blotting. Protein ( $20 \mu \mathrm{g})$ was resolved by $12.5 \%$ SDS-PAGE, transferred onto the PVDF membrane, and immunoblotted with the indicated antibodies. Actin was used as loading control. The Western data are representative of two or three independent experiments. "p $<0.05$ compared with the Tempol-untreated control cell group.

$\mathbf{A}$

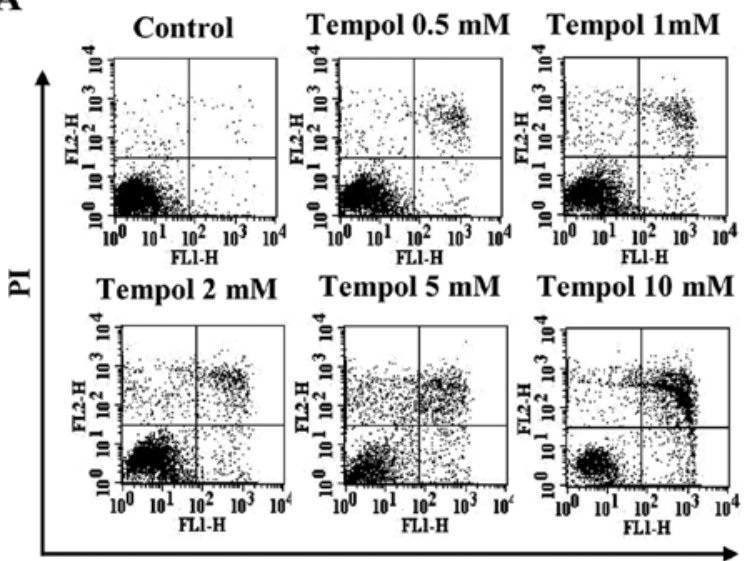

Annexin V FITC

B

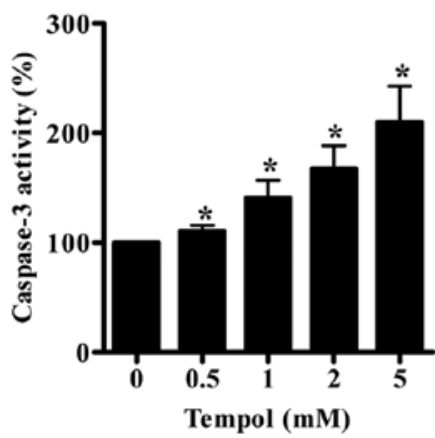

C

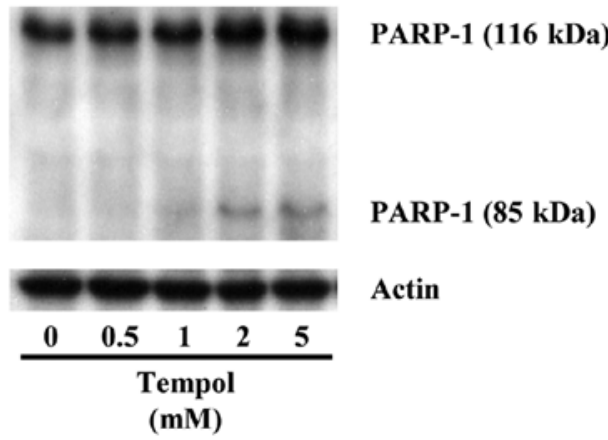

Figure 4. Effect of Tempol on apoptosis in As4.1 cells. Exponentially growing cells were treated with the indicated concentrations of Tempol for $48 \mathrm{~h}$. (A) Annexin V-FITC and/or PI staining cells were measured using a FACStar flow cytometer. The graph shows the percent of Annexin V positive cells. (B) Caspase-3 activity in Tempol-treated and -untreated As4.1 cells. (C) Samples of protein extracts were resolved by SDS-PAGE gel, transferred onto the PVDF membranes, and immunoblotted with antibodies against PARP-1 and actin. ${ }^{*} \mathrm{p}<0.05$ compared with the Tempol-untreated control group.

in Tempol-treated As4.1 cells, implying that PARP-1 was degraded in Tempol-treated cells (Fig. 4C).

To elucidate the effect of Tempol on MMP $(\Delta \Psi \mathrm{m})$ using Rhodamine 123 , cells were treated with the indicated doses of Tempol for $48 \mathrm{~h}$ (Fig. 5). Treatment with Tempol induced the loss of MMP $(\Delta \Psi \mathrm{m})$ in As4.1 cells in a dose-dependent manner.
To determine whether the loss of MMP $(\Delta \Psi \mathrm{m})$ cells were dead or not, we stained cells with PI to verify the disruption of the plasma membrane. As shown in Fig. 4, many of the negative Rhodamine 123 fluorescence cells showed PI positive staining, which indicated that many cells showing the loss of MMP $(\Delta \Psi \mathrm{m})$ were considered to be dead. 

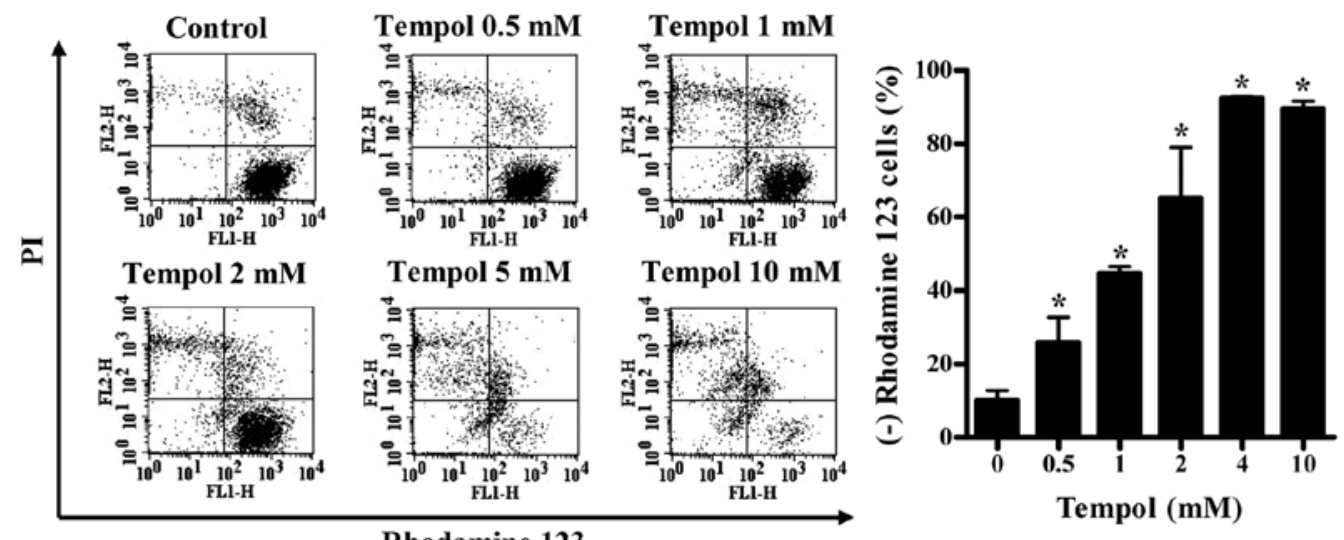

Figure 5. Effects of Tempol on MMP $(\Delta \Psi \mathrm{m})$ in As4.1 cells. Exponentially growing cells were treated with the designated doses of Tempol for $48 \mathrm{~h}$. The graph shows the percents of rhodamine 123 negative $(\Delta \Psi \mathrm{m}$ loss) cells, as measured using a FACStar flow cytometer. "p $<0.05$ compared with Tempol-untreated control group.

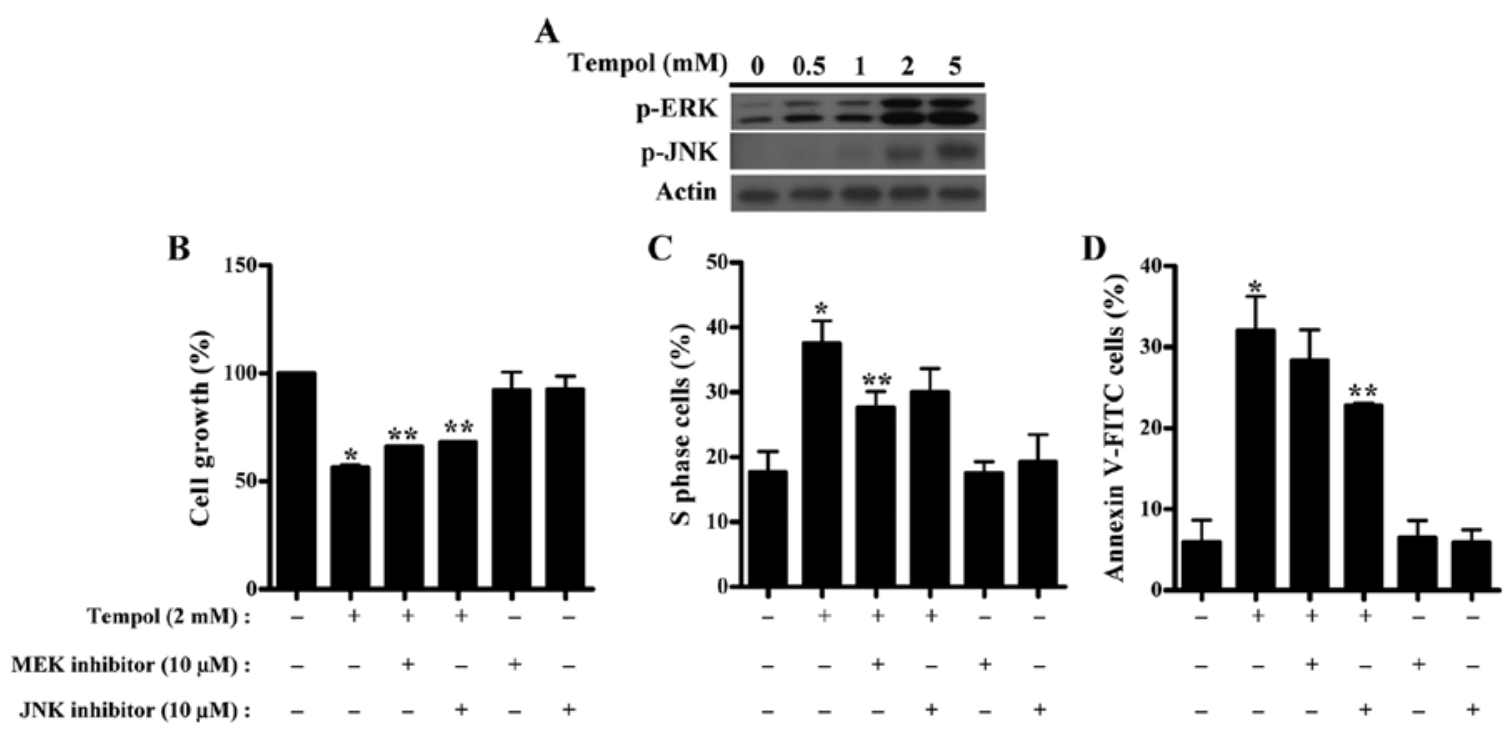

Figure 6. Effects of MEK and JNK inhibitors on cell growth, cell cycle and cell death in Tempol-treated As4.1 cells. Exponentially growing cells were treated with $2 \mathrm{mM}$ Tempol with or without MEK and JNK inhibitors for $48 \mathrm{~h}$. (A) Kinetics of MAPKs activation induced by Tempol at $48 \mathrm{~h}$. (B) Cell growth measured by an MTT assay. (C) The percent of S phase assayed by a FACStar flow cytometer. (D) The percent of Annexin V positive staining cells. " $\mathrm{p}<0.05$ compared with Tempol-untreated control group. ${ }^{* *}$ p $<0.05$ compared with Tempol-treated group.

Effects of MAPK inhibitors on cell growth, cell cycle and apoptosis in Tempol-treated As4.1 cells. To determine whether Tempol activates MAPKs, cells were treated with MAPK inhibitors at a concentration of $10 \mu \mathrm{M}$ and the states. Since the phosphorylation status of specific sites on MAPKs indirectly indicates the quantity of their activities, their phosphorylation status in Tempol-treated As4.1 cells was examined by Western blotting at $48 \mathrm{~h}$. Tempol increased the phosphorylation of ERK and JNK in a dose-dependent manner compared with Tempol-untreated control cells (Fig. 6A). However, it did not affect that of p38 (data not shown). Next, we examined the effects of MAPK inhibitors on cell growth, cell cycle and apoptosis in Tempol-treated As4.1 cells. As shown in Fig. 6B, treatment with MEK and JNK inhibitors significantly prevented growth inhibition of As 4.1 cells. While MEK inhibitor significantly decreased the percent of S phase, JNK inhibitor did not (Fig. 6C). JNK inhibitor reduced the number of Annexin $\mathrm{V}$ positive staining cells $\sim 10 \%$ in Tempol-treated cells. Treatment with each inhibitor did not affect cell growth, cell cycle and apoptosis in control cells (Fig. 6).

Effects of MEK or JNK inhibitor on intracellular ROS and GSH levels in Tempol-treated As4.1 cells. Next, we analyzed the changes of ROS and GSH levels in As4.1 cells in the presence of Tempol and/or MEK or JNK inhibitor. MEK inhibitors significantly increased intracellular ROS (DCF) level such as $\mathrm{H}_{2} \mathrm{O}_{2}$ in Tempol-treated As4.1 cells (Fig. 7A). Although MEK inhibitors significantly elevated ROS level in Tempol-treated cells, JNK inhibitors did not alter ROS level in Tempoltreated and -untreated cells (Fig. 7A). When we detected the intracellular $\mathrm{O}_{2}{ }^{-}$levels in Tempol-treated As4.1 cells, red fluorescence derived from DHE reflecting intracellular $\mathrm{O}_{2}{ }^{--}$level was not changed in As4.1 cells. However, neither inhibitor significantly changed $\mathrm{O}_{2}{ }^{-1}$ levels in Tempol-treated As4.1 cells or -untreated control cells (Fig. 7B). 

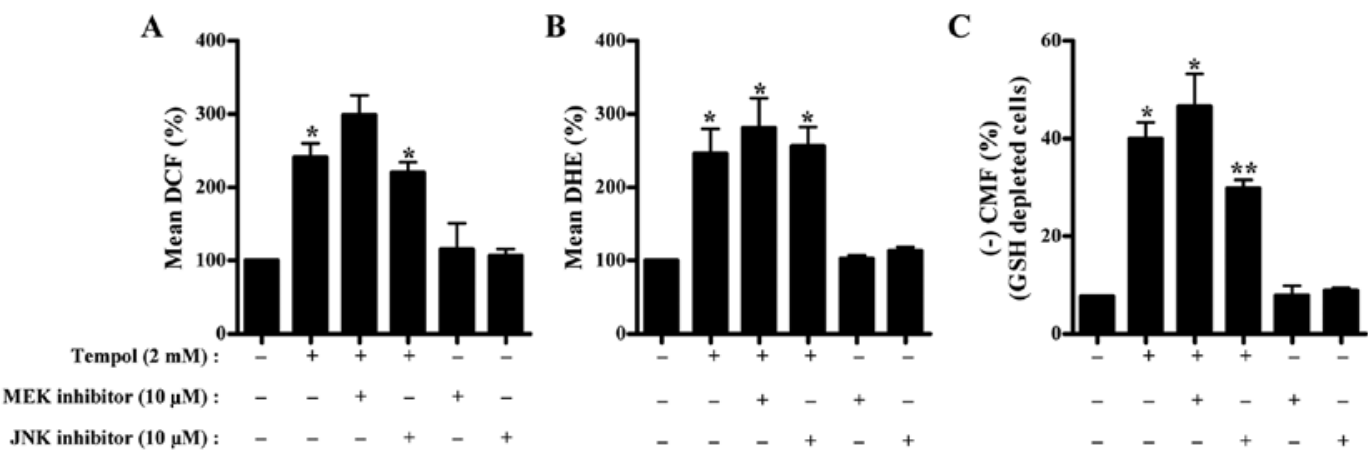

Figure 7. Effects of MEK and JNK inhibitors on intracellular ROS levels and GSH depletion in Tempo-treated As4.1 cells. Exponentially growing cells were treated with $2 \mathrm{mM}$ Tempol with or without MEK and JNK inhibitors. (A) Intracellular ROS levels. (B) Intracellular superoxide levels. (C) The percentage of GSH-depleted cells. ${ }^{*}<0.05$ compared with Tempol-untreated control group. ${ }^{* *} \mathrm{p}<0.05$ compared with Tempol-treated group.

In addition, we analyzed the changes of GSH levels in As4.1 cells in the presence of Tempol and/or MEK or JNK inhibitor. Tempol increased the number of GSH depleted cells in As4.1 cells by $\sim 30 \%$ compared with control cells at $48 \mathrm{~h}$ (Fig. 7C). JNK inhibitor significantly reduced the number in Tempol-treated As4.1 cells. Neither MEK or JNK inhibitor altered GSH level in As4.1 control cells (Fig. 7C).

\section{Discussion}

In the present study, we focused on evaluating the effects of Tempol on juxtaglomerular As4.1 cells in relation to cell growth and death. According to our results, Tempol significantly decreased the population and cell growth of As4.1 cells for $48 \mathrm{~h}$ in a dose-dependent manner, which was accompanied with the increase in intracellular ROS levels. Much evidence suggests that Tempol acts as an antioxidant agent at $5 \mathrm{mM}$ concentration in lens epithelial cells (17), hepatic satellite cells (18), and endothelial cells (19). In contrast, it is also reported that Tempol exhibits cytoxic effects by inducing excessive ROS at concentration as low as $1 \mathrm{mM}$ in Chinese hamster ovary cells (20), breast cancer cells (6) and human leukemia HL-60 cells (21). Our results indicate that Tempol as a pro-oxidant inhibits cell growth in As4.1 cells. Although the mechanisms underlying ROS generation after Tempol treatment was not clearly explained, it seems that Tempol localized on mitochondria directly induces mitochondrial dysfunction, which results in excessive ROS generation (4). Therefore, the apparent paradoxical effect of Tempol in different cells could be explained by assuming that each cell has different basal activities of mitochondria and on antioxidant enzymes.

Suppression of cell growth by Tempol can be explained in part by arrest during the cell cycle (22). DNA flow cytometric analysis indicated that treatment with $0.5-1 \mathrm{mM}$ Tempol significantly induced $\mathrm{S}$ phase arrest of the cell cycle at $48 \mathrm{~h}$. These concentrations did not induced similar level of cell death as evidenced by Annexin V/PI staining implying that the $\mathrm{S}$ phase arrest by Tempol can be considered as one of the pathways to suppress the growth of As4.1 cells. Treatment with 5 and $10 \mathrm{mM}$ Tempol inhibited cell growths without the change of cell cycle distribution compared to the As4.1 control cells. Thus, it is likely that $>5 \mathrm{mM}$ Tempol nonspecifically extended all phases of the cell cycle. The $\mathrm{S}$ phase arrest in Tempoltreated As4.1 cells was accompanied with the alteration of cell cycle-related proteins. Treatment with Tempol showed the down-regulation of cyclin-dependent kinase inhibitor p27, which forms complexes with CDKs and cyclins related to the progression of the G1 phase and G2/M phase, and inhibits their activity (23). These data indirectly support the result that Tempol could induce an S phase arrest rather than a G1 phase and/or a G2/M phase arrest of the cell cycle. Among the CDKs and cyclin proteins that regulate the cell cycle, CDK2 and cyclin A are critical to the progression of $\mathrm{S}$ phase in the cell cycle (24). The production of cyclin A and its complex with CDK2 enables S phase progression (25). Tempol up-regulated the expression of CDK2 protein, but the level of cyclin A was decreased in Tempol-treated cells. However, orderly S phase progression requires the down-regulation of E2F1 activity, which is partially accomplished by CDK-mediated phosphorylation (26). Inhibition of CDK activity during $S$ phase results in inappropriately persistent E2F, which can cause $\mathrm{S}$ phase delay (26) and apoptosis (27). Cyclin A mRNA and protein levels are known to be low before $S$ phase, but increased significantly during $\mathrm{S}$ and G2/M phases (28), which implies that the expression of cyclin $\mathrm{A}$ is increased during $\mathrm{S}$ phase. Therefore, $\mathrm{S}$ phase arrest in Tempol-treated As4.1 cells did not result from the shortage of cyclin A. We cannot exclude the possibility that the activity of cyclin A-CDK2 complex was decreased by Tempol treatment, consequently causing the $\mathrm{S}$ phase arrest.

According to our result, the intracellular ROS including $\mathrm{O}_{2}{ }^{--}$were increased in parallel with depletion of GSH in Tempol-treated As4.1 cells. Thus, it is likely that ROS formation due to Tempol may cause mitochondrial dysfunction and subsequent cytochrome c release, which lead to apoptosis (29). Concerning apoptosis, cytochrome c forms an apoptosome that is composed of Apaf-1 and procaspase-9, resulting in the activation of caspase-9. Caspase- 9 activates the effecter procaspase, including procaspase-3, to carry out the process of apoptosis (30). Correspondingly, Tempol induced loss of MMP $(\Delta \Psi \mathrm{m})$ and activated caspase-3 in As4.1 cells. We also observed that the proportion of Annexin V-positive staining cells was similar to that of Rhodamine 123-negative staining cells. These results imply that the loss of MMP $(\Delta \Psi \mathrm{m})$ by Tempol leads to apoptosis in As4.1 cells.

Little is known about MAPK signaling in Tempol-induced growth inhibition. We found that Tempol activated ERK and JNK signaling in As4.1 cells. Treatment with MEK inhibitor, which presumably inhibited ERK signaling, prevented the 
growth inhibition and $\mathrm{S}$ phase arrest in Tempol-treated As4.1 cells. However, MEK inhibitors had no effects on cell death. This does not support the notion that ERK activation induces some genes for proliferation (31). Increasing evidence indicates that ERK activation results in apoptosis in certain cell types (32). Therefore, our results suggest that the signaling of ERK in Tempol-treated As4.1 cells is involved in growth inhibition by modulating the $\mathrm{S}$ phase. Regarding JNK signaling, much evidence demonstrates that JNK signaling is responsible for cell death (33). Treatment with JNK inhibitor increased cell growth and decreased the number of Annexin V staining cells in Tempol-treated As4.1 cells. Therefore, JNK signaling in Tempol-treated As4.1 cells might be tightly involved in the cell death pathway rather than the cell cycle. Interestingly, neither inhibitor altered ROS levels in Tempol-treated As4.1 cells or control cells. These data suggest that increase in ROS levels by Tempol activates ERK and JNK downstream signaling. The relationships among ROS, MAPK signaling and Tempol in cell survival or cell death pathways needs further study.

In summary, Tempol dose-dependently inhibited the growth of As4.1 cells via inducing $\mathrm{S}$ phase arrest and triggering cell death. Tempol also activated ERK and JNK signaling, which was responsible for cell cycle and cell death, respectively. Our present data provide useful information for the toxicological effects of Tempol in juxtaglomerular cells in relation to cell growth inhibition and cell death.

\section{Acknowledgements}

This research was supported by Basic Science Research Program through the National Research Foundation of Korea (NRF) funded by the Ministry of Education, Science and Technology (2010-0007059).

\section{References}

1. Samuni A, Krishna CM, Mitchell JB, Collins CR and Russo A: Superoxide reaction with nitroxides. Free Radic Res Commun 9 241-249, 1990.

2. Wilcox CS: Effects of tempol and redox-cycling nitroxides in models of oxidative stress. Pharmacol Ther 126: 119-145, 2010.

3. Mitchell JB, Samuni A, Krishna MC, DeGraff WG, Ahn MS, Samuni U and Russo A: Biologically active metal-independent superoxide dismutase mimics. Biochemistry 29: 2802-2807, 1990.

4. Goralska M, Holley B and McGahan MC: The effects of Tempol on ferritin synthesis and $\mathrm{Fe}$ metabolism in lens epithelial cells. Biochim Biophys Acta 1497: 51-60, 2000.

5. Sies $\mathrm{H}$ and Mehlhorn R: Mutagenicity of nitroxide-free radicals. Arch Biochem Biophys 251: 393-396, 1986.

6. Gariboldi MB, Lucchi S, Caserini C, Supino R, Oliva C and Monti E: Antiproliferative effect of the piperidine nitroxide TEMPOL on neoplastic and nonneoplastic mammalian cell lines. Free Radic Biol Med 24: 913-923, 1998.

7. Blenis J: Signal transduction via the MAP kinases: proceed at your own RSK. Proc Natl Acad Sci USA 90: 5889-5892, 1993.

8. Kim WH, Goo SY,Lee KH and Park SJ: Vibrio vulnificus-induced cell death of human mononuclear cells requires ROS-dependent activation of p38 and ERK 1/2 MAPKs. Immunol Invest 38: 31-48, 2009.

9. Hsin YH, Chen CF, Huang S, Shih TS, Lai PS and Chueh PJ: The apoptotic effect of nanosilver is mediated by a ROS- and JNK-dependent mechanism involving the mitochondrial pathway in NIH3T3 cells. Toxicol Lett 179: 130-139, 2008.

10. Guyton KZ, Liu Y, Gorospe M, Xu Q and Holbrook NJ: Activation of mitogen-activated protein kinase by $\mathrm{H}_{2} \mathrm{O}_{2}$. Role in cell survival following oxidant injury. J Biol Chem 271: 4138-4142, 1996.
11. Turner J, Biesecker B, Leib J, Biesecker L and Peters KF: Parenting children with Proteus syndrome: experiences with, and adaptation to, courtesy stigma. Am J Med Genet A 143A: 2089-2097, 2007

12. Han YH, Moon HJ, You BR, Kim SZ, Kim SH and Park WH: Effects of carbonyl cyanide p-(trifluoromethoxy) phenylhydrazone on the growth inhibition in human pulmonary adenocarcinoma Calu-6 cells. Toxicology 265: 101-107, 2009.

13. Han YH, Kim SZ, Kim SH and Park WH: Pyrogallol inhibits the growth of lung cancer Calu- 6 cells via caspase-dependent apoptosis. Chem Biol Interact 177: 107-114, 2009.

14. Han YH, Moon HJ, You BR and Park WH: The effects of MAPK inhibitors on pyrogallol-treated Calu- 6 lung cancer cells in relation to cell growth, reactive oxygen species and glutathione. Food Chem Toxicol 48: 271-276, 2010.

15. Han YW, Kim SZ, Kim SH and Park WH: The changes of intracellular $\mathrm{H}_{2} \mathrm{O}_{2}$ are an important factor maintaining mitochondria membrane potential of antimycin A-treated As4.1 juxtaglomerular cells. Biochem Pharmacol 73: 863-872, 2007.

16. Porter AG and Janicke RU: Emerging roles of caspase-3 in apoptosis. Cell Death Differ 6: 99-104, 1999.

17. Reddan J, Sevilla M, Giblin F, Padgaonkar V, Dziedzic D, Leverenz V, Misra I and Peters J: The superoxide dismutase mimic TEMPOL protects cultured rabbit lens epithelial cells from hydrogen peroxide insult. Exp Eye Res 56: 543-554, 1993.

18. Zou C, Gao S, Zhao Y, Li S, Cao X, Zhang Y and Zhang K: Homocysteine enhances cell proliferation in hepatic myofibroblastic stellate cells. J Mol Med (Berl) 87: 75-84, 2009.

19. Haj-Yehia A, Nassar T, Assaf P, Nassar H and Anggard E: Effects of the superoxide dismutase-mimic compound TEMPOL on oxidant stress-mediated endothelial dysfunction. Antioxid Redox Signal 1: 221-232, 1999

20. Ankel E, Lai C, Hopwood L and Zivkovic Z: Cytotoxicity of commonly used nitroxide radical spin probes. Life Sci 40: 495-498, 1987.

21. Monti E, Supino R, Colleoni M, Costa B, Ravizza R and Gariboldi M: Nitroxide TEMPOL impairs mitochondrial function and induces apoptosis in HL60 cells. J Cell Biochem 82: 271-276, 2001.

22. Gariboldi M, Rimoldi V, Supino R, Favini E and Monti E: The nitroxide Tempol induces oxidative stress, p21WAF1/CIP1, and cell death in HL60 cells. Free Radic Biol Med 29: 633-641, 2000.

23. Kastan MB and Bartek J: Cell-cycle checkpoints and cancer. Nature 432: 316-323, 2004

24. Massague J: G1 cell-cycle control and cancer. Nature 432: 298-306, 2004

25. Ford HL and Pardee AB: The $S$ phase: beginning, middle, and end: a perspective. J Cell Biochem 30-31: S1-S7, 1998.

26. Kitagawa M, Higashi H, Suzuki-Takahashi I, Segawa K, Hanks SK, Taya Y, Nishimura S and Okuyama A: Phosphorylation of E2F-1 by cyclin A-cdk2. Oncogene 10: 229-236, 1995.

27. Phillips AC and Vousden KH: E2F-1 induced apoptosis. Apoptosis 6: 173-182, 2001

28. Cho NH, Choi YP, Moon DS, Kim H, Kang S, Ding O, Rha SY, Yang YJ and Cho SH: Induction of cell apoptosis in non-small cell lung cancer cells by cyclin A1 small interfering RNA. Cancer Sci 97: 1082-1092, 2006.

29. Yang J, Liu X, Bhalla K, Kim CN, Ibrado AM, Cai J, Peng TI, Jones DP and Wang X: Prevention of apoptosis by Bcl-2: release of cytochrome c from mitochondria blocked. Science 275: 1129-1132, 1997.

30. Cohen GM: Caspases: the executioners of apoptosis. Biochem J 326: 1-16, 1997.

31. Torii S, Yamamoto T, Tsuchiya Y and Nishida E: ERK MAP kinase in $\mathrm{G}$ cell cycle progression and cancer. Cancer Sci 97: 697-702, 2006.

32. Kim YK, Kim HJ, Kwon CH, Kim JH, Woo JS, Jung JS and Kim JM: Role of ERK activation in cisplatin-induced apoptosis in OK renal epithelial cells. J Appl Toxicol 25: 374-382, 2005.

33. Verheij M, Bose R, Lin X, Yao B, Jarvis W, Grant S, Birrer M, Szabo E, Zon L, Kyriakis J, Haimovitz-Friedman A, Fuks Z and Kolesnick RN: Requirement for ceramide-initiated SAPK/ JNK signalling in stress-induced apoptosis. Nature 380: 75-79, 1996. 